\title{
Degradation of shear performance of screwed joints caused by wood decay
}

\author{
Rintaro Ueda ${ }^{1}$, Kei Sawata ${ }^{2 *}$, Ryuya Takanashi ${ }^{3}$, Yoshihisa Sasaki ${ }^{2}$ and Takanobu Sasaki ${ }^{2}$
}

\begin{abstract}
Shear tests were conducted on screwed joints with decayed main members, and the degradation of shear performance of screwed joints by wood decay was investigated. The differences between decayed and control specimens in yield load $\left(P_{\mathrm{y}}\right)$, and maximum load $\left(P_{\max }\right)$ were both significant at the $1 \%$ level, while the difference in the initial stiffness $\left(K_{s}\right)$ was not significant at the $5 \%$ level. The extent of decay was evaluated through Pilodyn penetration depth and the decay depth. Pilodyn penetration depth had no significant relationships with $K_{s^{\prime}} P_{y^{\prime}}$ or $P_{\max }$ of screwed joints. It is inferred that no significant relationship was found between Pilodyn penetration depth and the strength properties because the range of the measured Pilodyn penetration depth was narrow $(16-23.5 \mathrm{~mm})$. The decay depth had a significant inverse correlation with $K_{\mathrm{s}}$ of the decayed specimens. There was no significant relationship between the decay depth and $P_{y^{\prime}}$ or $P_{\max }$. Multiple regression analysis was conducted on $K_{s^{\prime}} P_{y^{\prime}}$ and $P_{\max }$ using the decay depth and sound wood density $\left(W D_{h}\right)$ as 2 explanatory variables. The multiple regression of $K_{s^{\prime}} P_{y^{\prime}}$ and $P_{\max }$ on the decay depth and $W_{h_{h}}$ were significant at the $1 \%, 5 \%$, and $1 \%$ level, respectively. $K_{s^{\prime}} P_{y^{\prime}}$ and $P_{\max }$ are inferred to be determined by both the decay depth and $W D_{h}$. The strength properties of screwed joints with one screw obtained in this study were compared with those of screwed joints with seven screws obtained in a previous study. The difference between $K_{\mathrm{s}^{\prime}} P_{\mathrm{y}^{\prime}}$ and $P_{\max }$ of the screwed joints with one screw and those of the screwed joints with seven screws was not significant at the $5 \%$ level. It is inferred that shear performance of screw joints with multiple screws are sufficiently estimated from those of screw joints with one screw by simply multiplying the strength properties, even if the main members were decayed.
\end{abstract}

Keywords: Wood decay, Screwed joints, Brown-rot fungus, Degradation of wood, Decay treatment

\section{Introduction}

When degradation of wood occurs in wooden construction, the degraded wood member is reinforced or partly replaced. However, the replacing of the timber might necessitate the disassembly of the wooden structure which is difficult, costly, and requires skills and knowledge. For these reasons, reinforcing is often preferred to repair the deteriorated wooden constructions. Among other causes of wood degradation, wood decay by brownrot fungi significantly degrades wood members. Most of structural damage to the indoors of buildings in Europe

\footnotetext{
*Correspondence: ksawata@for.agr.hokudai.ac.jp

${ }^{2}$ Research Faculty of Agriculture, Hokkaido University, N9 W9,

Sapporo 060-8589, Japan

Full list of author information is available at the end of the article
}

and North America is caused by brown-rot fungi [1], and it is estimated that approximately $80 \%$ of all in-service wood decay is caused by brown-rot fungi [2].

Numerous studies have reported on the effect of wood decay on the strength properties of wood such as bending strength [3-6] and compressive strength [7]. Although several studies have been conducted on the performances of joints with wood decay, the accumulated information is insufficient. Information on the remaining strength capacity of joints with decayed wood is required because the strength capacity of joints often affect the structural performance of the construction. Some studies that evaluate the degradation of shear performance of nailed joints caused by wood decay have already been reported [8-10].
Springer Open

(c) The Author(s) 2020. This article is licensed under a Creative Commons Attribution 4.0 International License, which permits use, sharing, adaptation, distribution and reproduction in any medium or format, as long as you give appropriate credit to the original author(s) and the source, provide a link to the Creative Commons licence, and indicate if changes were made. The images or other third party material in this article are included in the article's Creative Commons licence, unless indicated otherwise in a credit line to the material. If material is not included in the article's Creative Commons licence and your intended use is not permitted by statutory regulation or exceeds the permitted use, you will need to obtain permission directly from the copyright holder. To view a copy of this licence, visit http://creativecommons.org/licenses/by/4.0/. 
Screwed joints are used in combination with reinforcing equipment to reinforce the wooden constructions, however, only a few studies have been conducted [1113], and hence data on the strength degradation of those with decayed wood has been poorly accumulated. Furthermore, the deformation characteristics are unknown. In this study, we have investigated the effects of wood decay on the shear performance of screwed joints.

\section{Materials and methods}

\section{Specimens}

Figure 1 shows the outline of the specimens. The main members of the screwed joints were prepared from solid lumbers of Sakhalin fir (Abies sachalinensis) whose dimensions were $60 \mathrm{~mm}$ in width, $60 \mathrm{~mm}$ in thickness, and $300 \mathrm{~mm}$ in length. The average density was $442 \mathrm{~kg} /$ $\mathrm{m}^{3}$ (standard deviation $57.1 \mathrm{~kg} / \mathrm{m}^{3}$ ) and the average moisture content was $10.2 \%$ (standard deviation $0.804 \%$ ). These were measured from the sound part of the specimens after the shear tests. The number of main members prepared as decayed and control specimens were 12 and 9, respectively. Five out of nine control specimens had a width of $45 \mathrm{~mm}$ instead of $60 \mathrm{~mm}$. The load-slip curves of screwed joints with a width of $45 \mathrm{~mm}$ showed no difference with those with a width of $60 \mathrm{~mm}$ (Fig. 7).

The side members were steel plates with a thickness of $6 \mathrm{~mm}$, having 2 holes with a diameter of $9.0 \mathrm{~mm}$ for fixing to the test machine and a hole with a diameter of $6.1 \mathrm{~mm}$ for the screw. The main member and the side member were connected by a "TBA-65D" screw, which was designed to be used with hold-down hardware and made by Tanaka Co., Ltd. "TBA-65D" screws have an outer thread diameter of $6.0 \mathrm{~mm}$, core diameter of $4.0 \mathrm{~mm}$, full length of $69 \mathrm{~mm}$, and length with screw thread of $55 \mathrm{~mm}$ as shown in Fig. 2. Average yield point of the screws was $1117 \mathrm{~N} / \mathrm{mm}^{2}$, which was obtained from the bending tests conducted by Takanashi et al. [13].

\section{Decay treatment}

The species of fungus used was Fomitopsis palustris which is a type of brown-rot fungi [14]. Nutrient agar, floras of Fomitopsis palustris, and 17 small pieces (W16 $\times$ L16 $\times$ H8 mm) of Sakhalin fir were filled into congealed nutrient agar containers as shown in Fig. 3. The containers were placed in a closed environment at $28{ }^{\circ} \mathrm{C}$ and $75 \%$ relative humidity for 4 weeks until the hyphae grew sufficiently.

Furthermore, each container was attached to two wood specimens using stretch wrap and the specimens were placed in a closed environment at $28{ }^{\circ} \mathrm{C}$ and $75 \%$ relative humidity for 22 weeks. The center of the container coincided with the screwed point $(80 \mathrm{~mm})$ as shown in Figs. 1 and 4. After the decaying period elapsed, the containers were detached from the wood specimens. The specimens were placed in room temperature and humidity for 2 weeks to be air-dried.

The container in which floras of wood decay fungus and small wood pieces were put on congealed nutrient agar is called "rot fungus feeder unit". Decay tests using rot fungus feeder units have been conducted on nailed joints [8], multiple screwed joints [13], and column-sill joints [15]. This decaying method is suited to decay only a limited part of a wood member.

Decayed and air-dried wood members were connected to the steel plates by screws without predrilled hole, leaving a slight gap to avoid initial friction between main and side members. The end distance of screwed joints was $80 \mathrm{~mm}$.

\section{Test methods}

The main member and the side member were fastened to the testing machine and single shear tests were conducted on the screwed joints. The loading direction was parallel to the grain for the main member. The relative slips between the main and side members of the screwed joints were measured by two displacement transducers, located on the two sides of the main member as shown in Fig. 5.

The load was applied to a relative slip of $1.2 \mathrm{~mm}$, and subsequently, reduced to a relative slip of $0 \mathrm{~mm}$. This loading procedure was repeated to produce relative slips of 2.4, 4.8, and $9.6 \mathrm{~mm}$, and subsequently, the load was kept monotonically applied until the tests were terminated when the relative slips reached $30 \mathrm{~mm}$ or screw breakages occurred. The slip level was determined from the yield displacement obtained from the preliminary monotonic loading test of the screwed joints with an undecayed main member, which was $2.4 \mathrm{~mm}$, and the relative slips of $1.2,2.4,4.8,9.6 \mathrm{~mm}$ were equivalent to $1 / 2,1$, 2, 4 times of that yield displacement, respectively.

After the shear test, pin penetration depth using Pilodyn was measured near the location of the screwed point to evaluate the extent of decay. To determine the moisture content and wood density, subsamples were cut from the decayed and sound part of the main members. The size of subsamples from the decayed and sound part were approximately $20-60 \mathrm{~mm}$ in width, $60 \mathrm{~mm}$ in thickness, and $85-129 \mathrm{~mm}$ in length and $18-60 \mathrm{~mm}$ in width, $25-60 \mathrm{~mm}$ in thickness, and $20-45 \mathrm{~mm}$ in length, respectively.

Subsequently, all the specimens were cleaved to observe the failure modes of the screwed joints and determine the decay depth in the screwed point. The decay depth was obtained from the difference between the thickness of the main member and length of the sound part as shown in Fig. 6. 

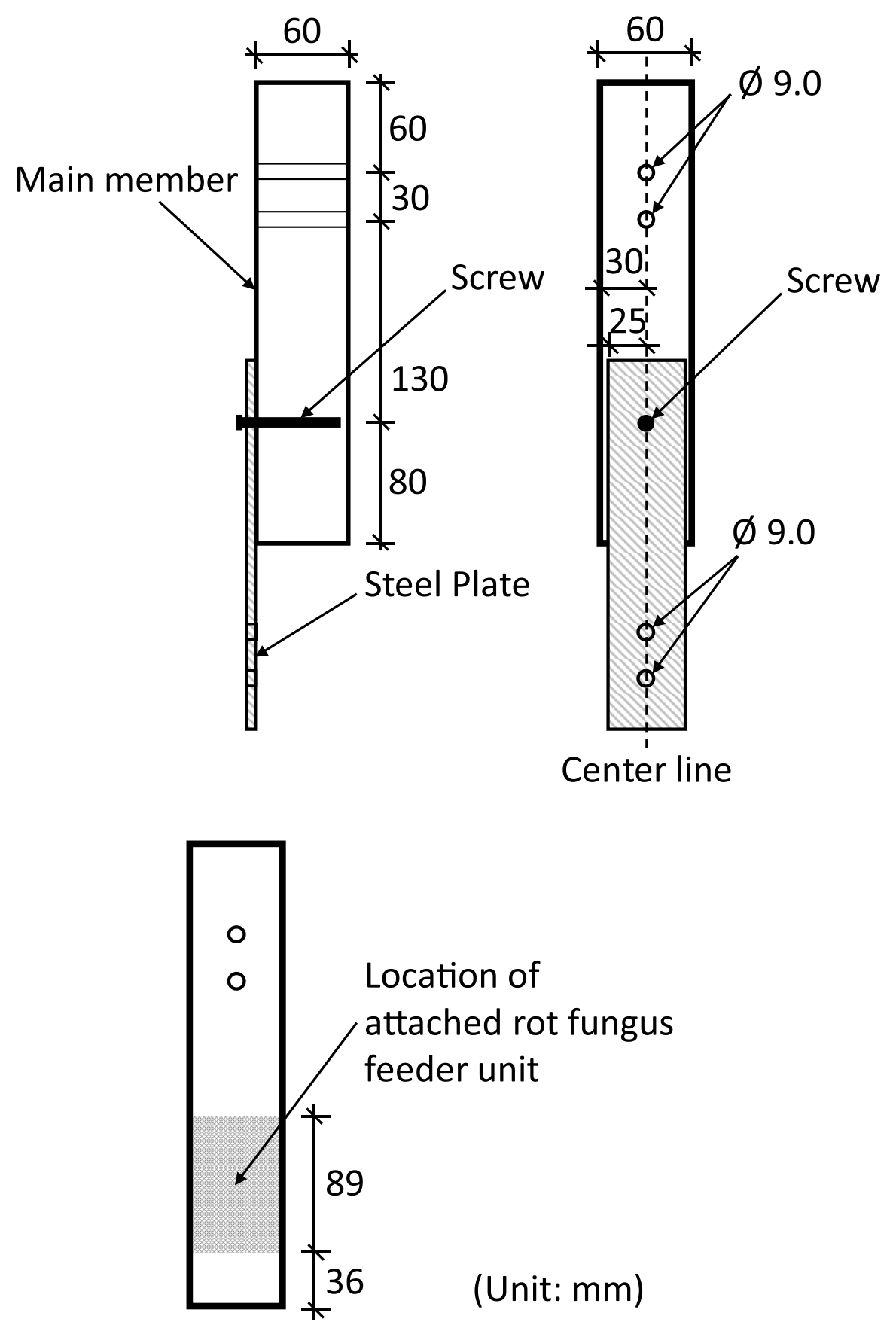

Fig. 1 Outline of the specimen

\section{Results and discussion}

\section{Envelop load-slip curve}

Figure 7 shows the envelop load-slip curves of the screwed joints. Decayed specimens had roughly lower loads than control specimens, as observed in the curves. The slopes of the load-slip curves up to $10 \mathrm{~mm}$ slip of decayed specimens had larger variables in comparison to those of control specimens. The points in the curves where the load drastically drops are the breaking points of the screws as shown in Fig. 8. The screws were ruptured in 11 out of 12 decayed specimens and 7 out of 9 control specimens and this result coincides with the 


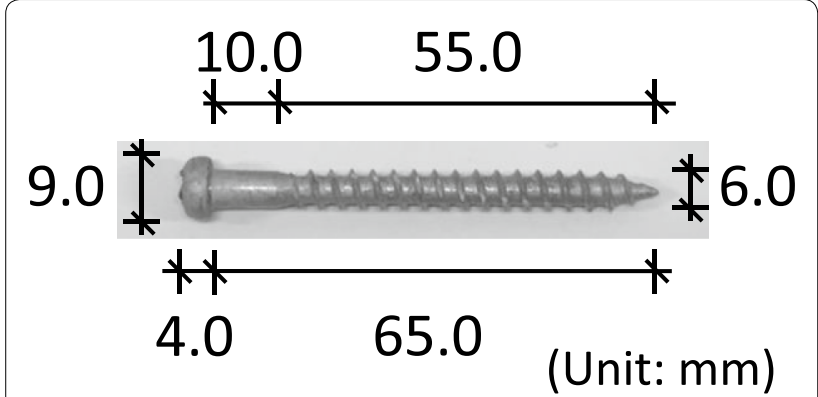

Fig. 2 Outline of the screw "TBA-65D"

number of curves in which the breaking points are observed.

To evaluate the shear performance of the joints, the maximum load $\left(P_{\max }\right)$, yield slips $\left(D_{\mathrm{y}}\right)$, yield load $\left(P_{\mathrm{y}}\right)$, and initial stiffness $\left(K_{\mathrm{s}}\right)$ are determined from the curve as follows [16]:

1. Two straight lines were drawn on the envelope loadslip curves. One line (line I in Fig. 9) passes through the 2 points on the curves corresponding to 10 and $40 \%$ of $P_{\max }$ and the other (line II in Fig. 9) passes through the 2 points corresponding to 40 and $90 \%$ of $P_{\max }$.

2. A straight line (line III in Fig. 9) was drawn as it has the same slope as line II and it is tangent to the curve.

3. The load and slip corresponding to the intersection of line I and III are obtained and defined as $P_{\mathrm{y}}$ and the yield slip, $D_{y}$, respectively. The slope of the line passing through the origin and the coordinate $D_{\mathrm{y}}^{-}$ and $P_{\mathrm{y}}$ is obtained and defined as $K_{\mathrm{s}}$.

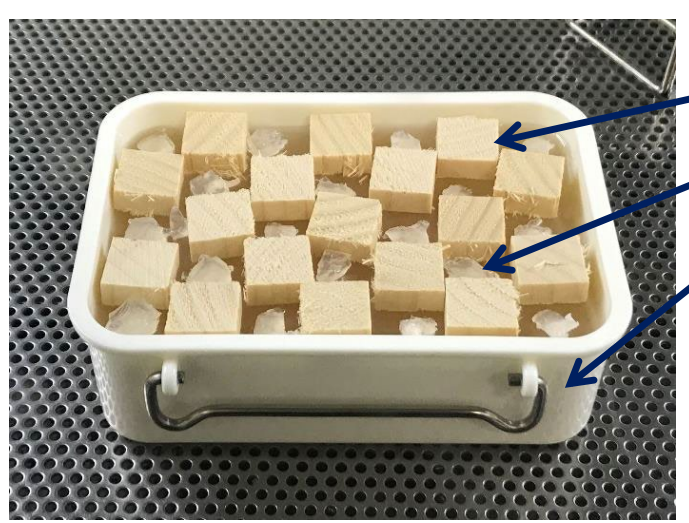

Small piece of Abies sachalinensis

$($ width $=16$, length $=16$, height $=8 \mathrm{~mm})$

Flora of Fomitopsis palustris

Polypropylene container

( width $=129$, length $=89$, depth $=43 \mathrm{~mm}$ )

Fig. 3 Rot fungus feeder unit

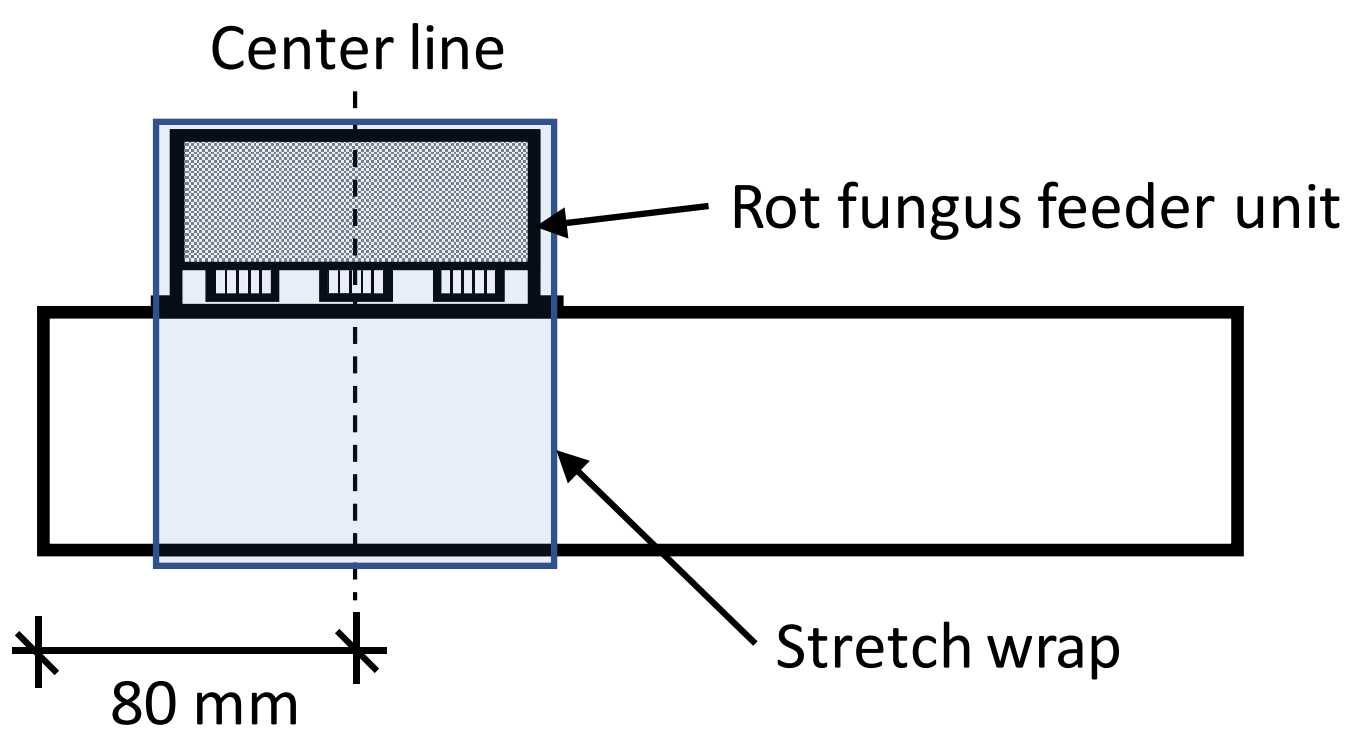

Fig. 4 Attachment of the rot fungus feeder unit 


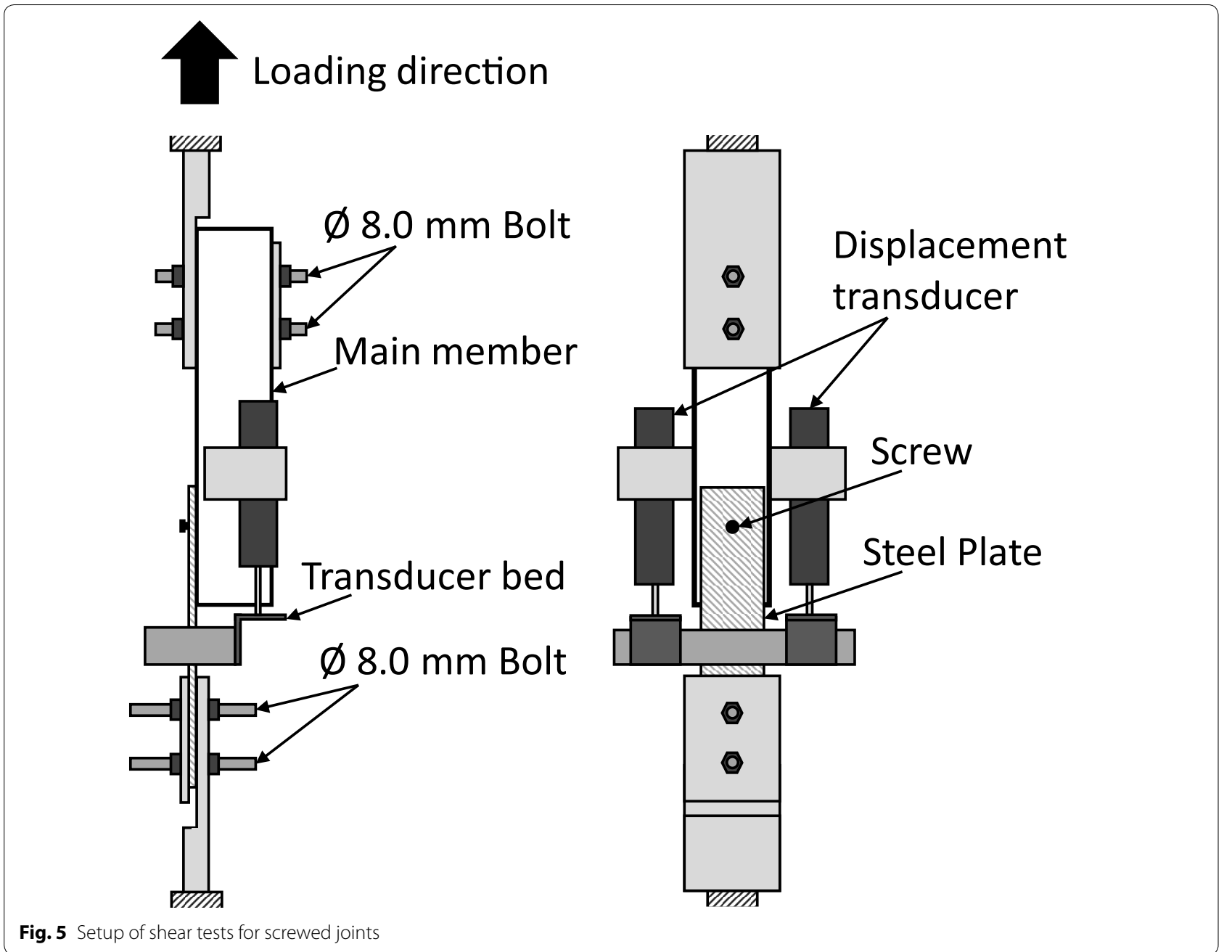

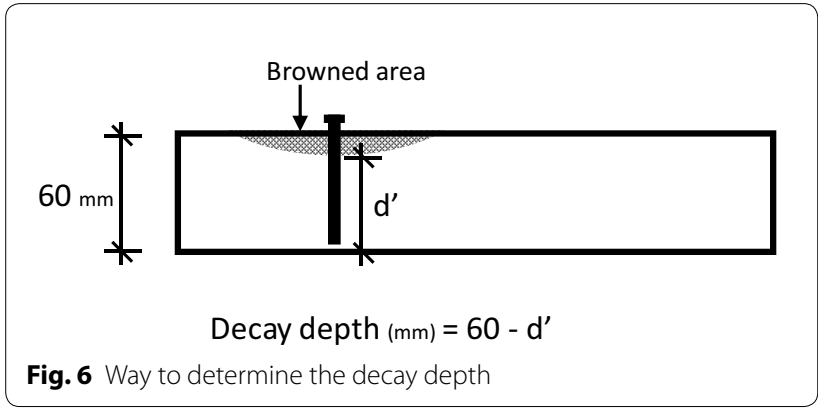

Three specimens ( 1 from decayed specimens and 2 from control specimens) could not be evaluated to obtain the yield load from this method because the slope of line I and line II was nearly the same. These specimens were evaluated to determine $P_{\mathrm{y}}, D_{\mathrm{y}}$, and $K_{\mathrm{s}}$ using 3 points on the curves corresponding to 10,60 , and $80 \%$ of $P_{\max }$ instead of those corresponding to 10,40 , and $90 \%$ of $P_{\max }$. In the case the specimens other than the three specimens were calculated $P_{\mathrm{y}}$ using 3 points on the curves corresponding to 10,60 , and $80 \%$ of $P_{\max }$, the values were 1.09 times in average of those corresponding to 10,40 , and $90 \%$ of $P_{\max }$. The former was close to the latter.

The values of $K_{\mathrm{s}},-P_{\mathrm{y}}$, and $P_{\max }$ are shown in Fig. 10. The difference between decayed and control specimens in $P_{\mathrm{y}}$ and $P_{\max }$ was both significant at the $1 \%$ level. However, the difference in $K_{\mathrm{s}}$ was not significant at the $5 \%$ level, though the mean of $K_{\mathrm{s}}$ of the control specimens was higher than that of the decayed specimens. This can be attributed to the large deviation in the values of $K_{\mathrm{s}}$ and presumably does not mean that $K_{\mathrm{s}}$ will not change even if the member was decayed, as is reported in preceding studies $[10,13]$.

\section{Evaluation of the extent of decay}

The extent of decay on the main members was evaluated by Pilodyn penetration depth and the decay depth. The relationships between Pilodyn penetration depth and $K_{\mathrm{s}}$, $P_{\mathrm{y}}$, and $P_{\max }$ are shown in Fig. 11. 

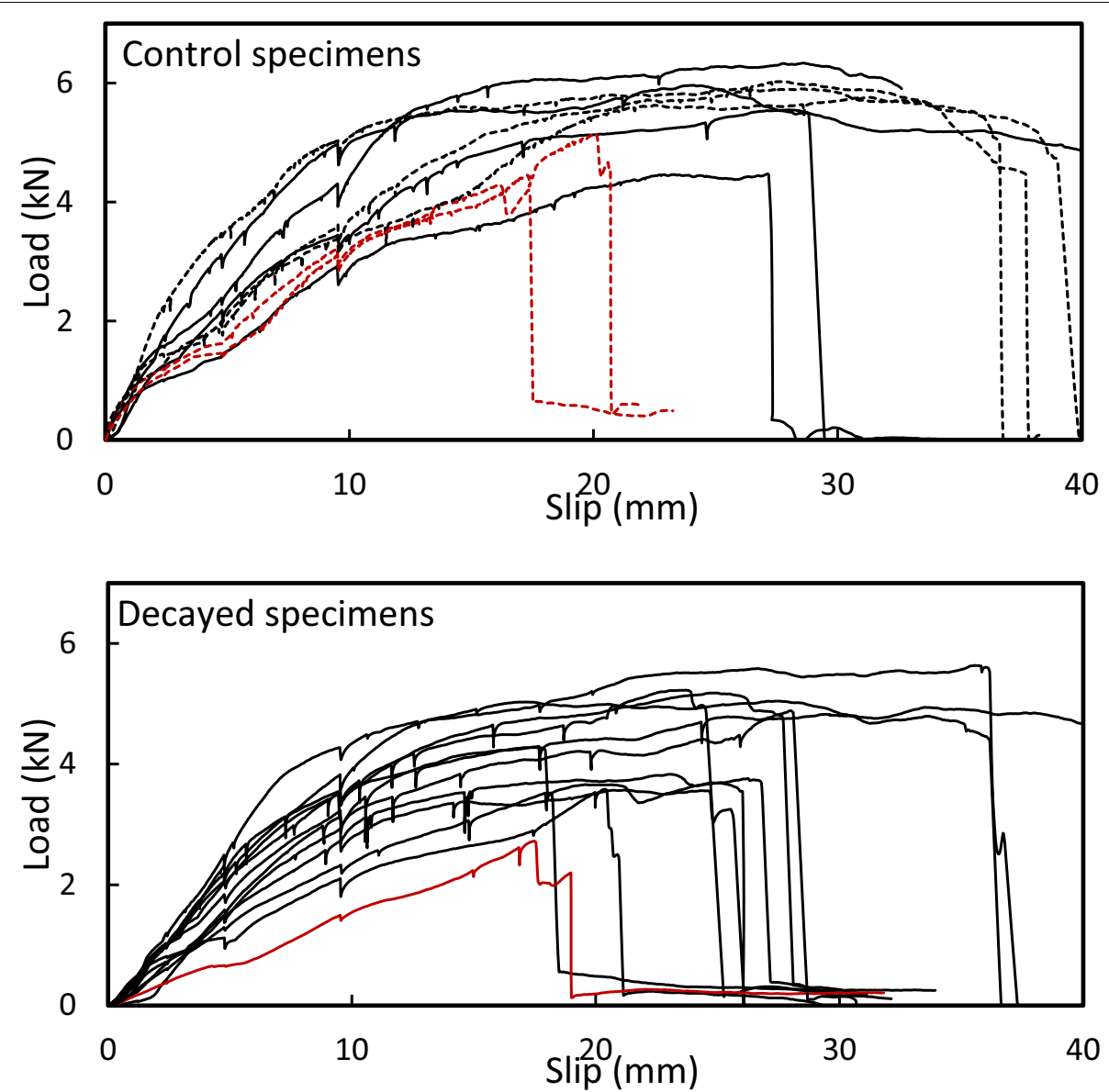

Fig. 7 Load-slip curves of screwed joints. Black line curves obtained yield load using 3 points on the curves corresponding to 10,40, and 90\% of the maximum load; red line curves obtained yield load using 3 points on the curves corresponding to 10,60, and 80\% of the maximum load; solid line curves of specimens with a width of $60 \mathrm{~mm}$; broken line curves of specimens with a width of $45 \mathrm{~mm}$

Pilodyn penetration depth had no significant relationships with $K_{\mathrm{s}}, P_{\mathrm{y}}$, or $P_{-}{ }_{\max }$. Mori et al. reported that Pilodyn penetration depth had an inverse correlation with the yield load of screwed joints with decayed wood [12]. The difference between these results would be attributed to the range of Pilodyn penetration depth obtained from the tests. Whereas the value of Pilodyn penetration depth measured by Mori et al. ranged from 10 to over $40 \mathrm{~mm}$, the value of Pilodyn penetration depth in this study was 16.0 to $23.5 \mathrm{~mm}$. It is inferred that no significant relationship was found between Pilodyn penetration depth and the strength properties in this study because the value of Pilodyn penetration depth was not so widely ranged, and did not cover the whole length of the part with screw thread.

The relationships between decay depth and $K_{\mathrm{s}}, P_{\mathrm{y}}$, and $P_{\max }$, are shown in Fig. 12. The decay depth had a significant inverse correlation with $K_{\mathrm{s}}$ at the $1 \%$ level and $K_{\mathrm{s}}$ corresponding to $20 \mathrm{~mm}$ of decay depth was about
0.5 times that of the mean of control specimens. $P_{\mathrm{y}}$ and $P_{\max }$ corresponding to $20 \mathrm{~mm}$ of decay depth were also 0.5 times those of the mean of control specimens, respectively, however, the decay depth had no significant relations with $P_{\mathrm{y}}$ or $P_{\max }$ at the $5 \%$ level.

\section{Multiple regression of the shear performance on the decay depth and the sound wood density}

Multiple regression analysis was conducted on screwed joints with decayed wood using $K_{\mathrm{s}}$ as a dependent variable and the decay depth and the sound wood density $\left(\mathrm{WD}_{\mathrm{h}}\right)$ as 2 explanatory variables. The result of multiple regression analysis is listed in Table 1 . The multiple determination coefficient $\left(R_{-}^{2}\right)$ of $K_{\mathrm{s}}$ was 0.85 . The multiple regression was significant at the $1 \%$ level and the decay depth and $\mathrm{WD}_{\mathrm{h}}$ were both significant as the explanatory variable at the $1 \%$ level. Therefore, $K_{\mathrm{s}}$ of decayed specimens is inferred to be determined by both the decay depth and $\mathrm{WD}_{\mathrm{h}}$. 


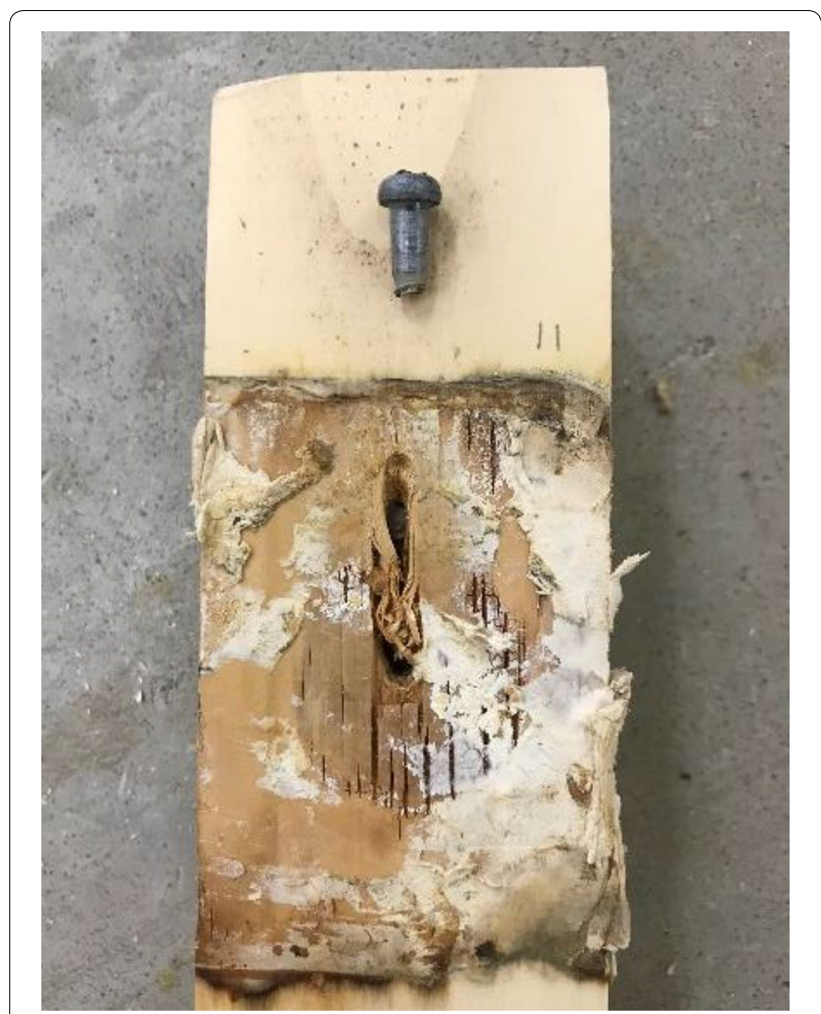

Fig. 8 Ruptured screw and the specimen after the test

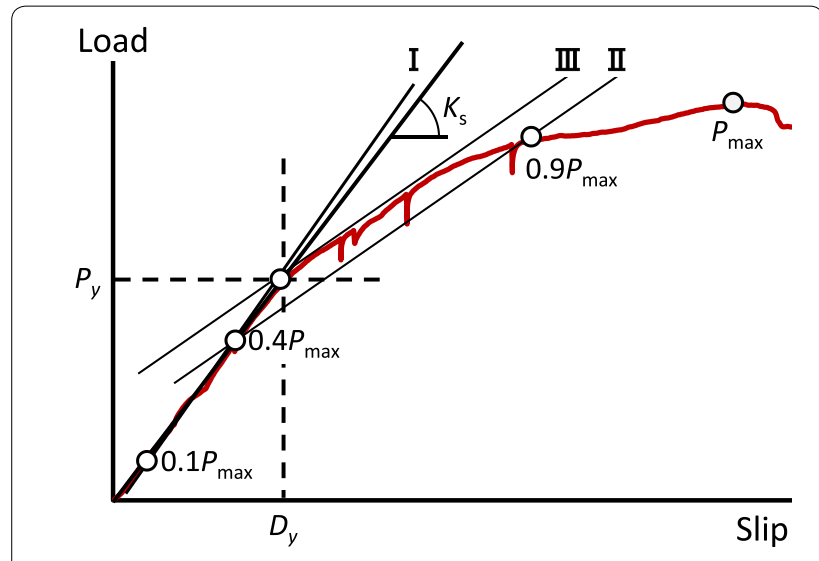

Fig. 9 Method of evaluating shear performance of screwed joints. Note: $P_{\text {max }}$ maximum load; $P_{y^{\prime}}$ yield load; $D_{y^{\prime}}$ yield slip; $K_{\mathrm{s}^{\prime}}$ initial stiffness

Likewise, multiple regressions of $P_{\mathrm{y}}$ and $P_{\max }$ on the decay depth and $\mathrm{WD}_{\mathrm{h}}$ were obtained, respectively. The multiple regression of $P_{\mathrm{y}}$ was significant at the $5 \%$ level and as explanatory variables, the decay depth and $\mathrm{WD}_{\mathrm{h}}$ were both significant at the $5 \%$ level. The multiple regression of $P_{\max }$ was significant at the $1 \%$ level and as
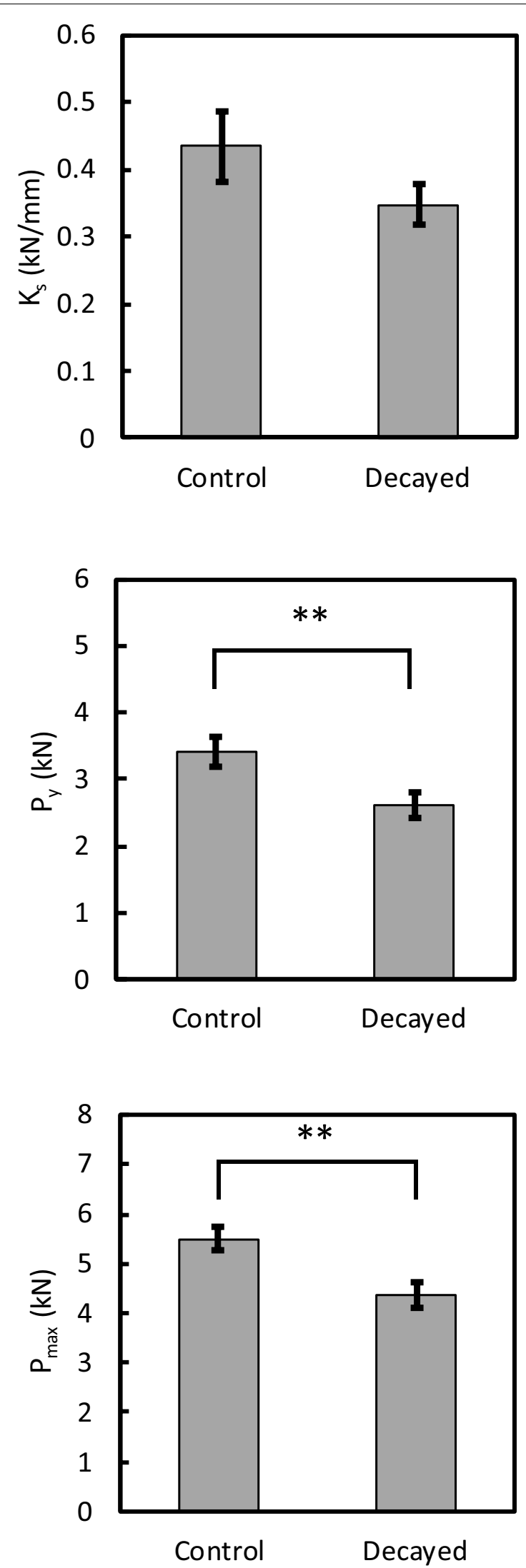

Fig. 10 Values of $K_{\mathrm{s}^{\prime}} P_{\mathrm{y}^{\prime}}$ and $P_{\max }$ 

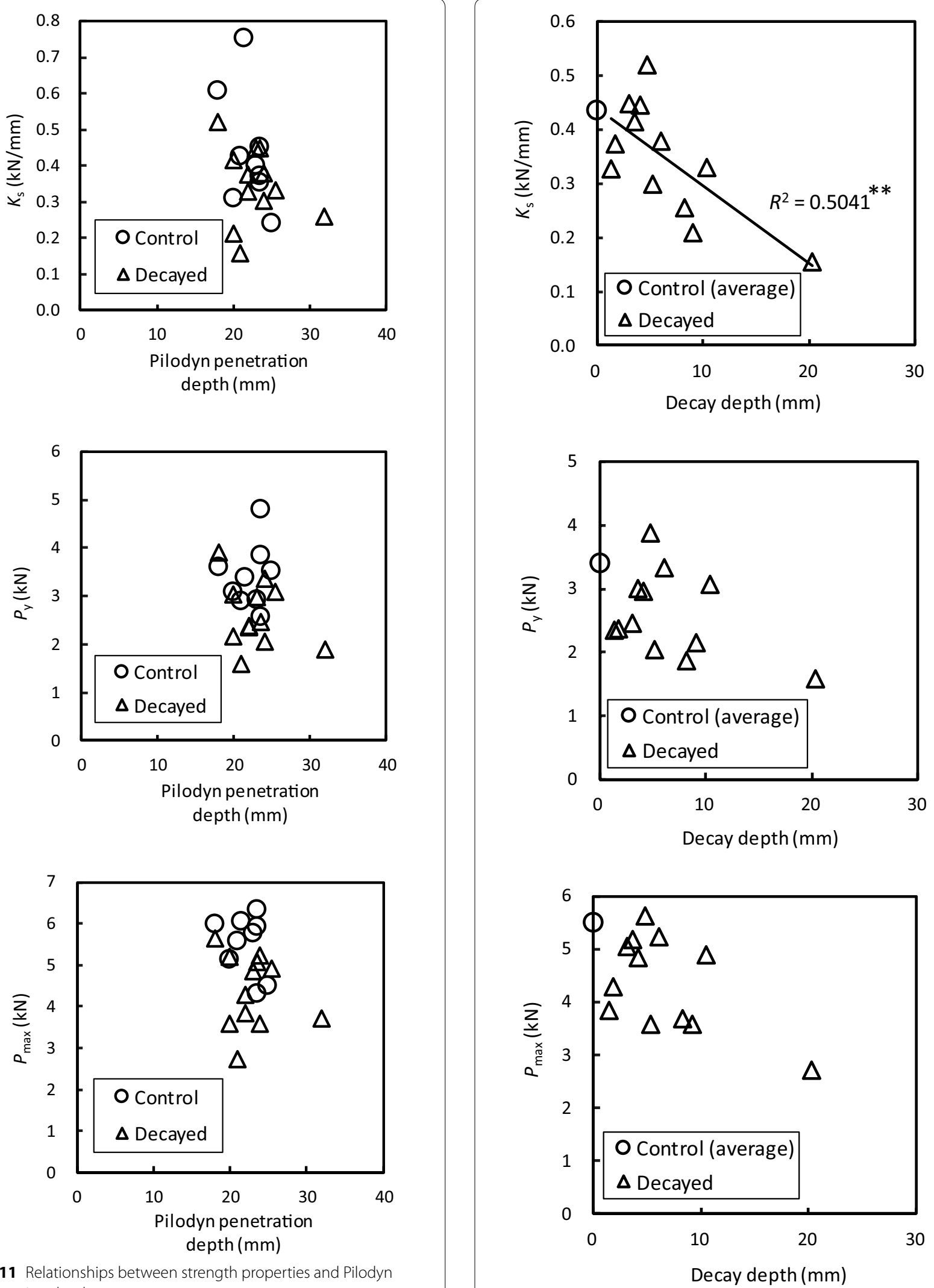

Fig. 11 Relationships between strength properties and Pilodyn penetration depth

Fig. 12 Relationships between strength properties and the decay depth. Note: ${ }^{* *}=$ significant at the $1 \%$ level 
Table 1 Coefficients and determination coefficient $\left(R^{2}\right)$ of multiple regressions of $K_{s^{\prime}}, P_{y^{\prime}}$ and $P_{\max }$ on the decay depth and $W D_{h}$

\begin{tabular}{|c|c|c|c|c|}
\hline \multirow[t]{3}{*}{$Y$} & \multicolumn{3}{|c|}{ Multiple regression: } & \multirow[t]{3}{*}{$R^{-2}$} \\
\hline & \multicolumn{3}{|c|}{$Y=a D+b W D_{h}+c$} & \\
\hline & $a$ & $b$ & $c$ & \\
\hline$K_{s}$ & -0.0176 & 0.00130 & -0.141 & $0.85^{* *}$ \\
\hline$P_{y}$ & -0.0734 & 0.00838 & -0.827 & $0.53^{*}$ \\
\hline$P_{\max }$ & -0.1243 & 0.01206 & -0.433 & $0.74^{* *}$ \\
\hline
\end{tabular}

$D=$ decay depth $(\mathrm{mm})$

$W D_{\mathrm{h}}=$ sound wood density $\left(\mathrm{kg} / \mathrm{m}^{3}\right)$

* Significant at the $5 \%$ level. ** significant at the $1 \%$ level

explanatory variables, the decay depth and $\mathrm{WD}_{\mathrm{h}}$ were both significant at the $1 \%$ level. The multiple determination coefficients for $P_{\mathrm{y}}$ and $P_{\max }$ were 0.53 and 0.74 , respectively, and those values were significant at the $5 \%$ and $1 \%$ level, respectively. $P_{\mathrm{y}}$ and $P_{\max }$ of screwed joints with decayed wood also could be estimated by both the decay depth and $\mathrm{WD}_{\mathrm{h}}$.

\section{Comparison with the screwed joints with multiple screws of previous study}

Previously, Takanashi et al. conducted a research on the screwed joints with seven screws using the same wood species and screws as this study and reported the effect of decay of the main members on the shear strength [13]. Therefore, in this study, we conducted a comparison between joints with a screw and those with multiple screws regarding the effect of decay. The value of Pilodyn penetration depth in the study of Takanashi et al. was about $20-30 \mathrm{~mm}$ and the extent of decay of decayed specimens is inferred to be the same as this study. The strength properties per screw of the screwed joints are shown in Fig. 13.

The difference in $K_{\mathrm{s}}$ per screw between screwed joints with one screw and those with seven screws was not significant at the $5 \%$ level, regardless of the decay. The differences in $P_{\mathrm{y}}$ and $P_{\max }$ per screw were not significant at the $5 \%$ level as well. This means that shear performance of the screwed joints with seven screws can be sufficiently estimated from the results of the loading tests of the screwed joints with one screw. This holds true even if the main members were decayed, so long as the extent of decay is the same.

\section{Conclusions}

Shear tests were conducted on screwed joints with a decayed main member and the degradation of shear performance of screwed joints by wood decay was
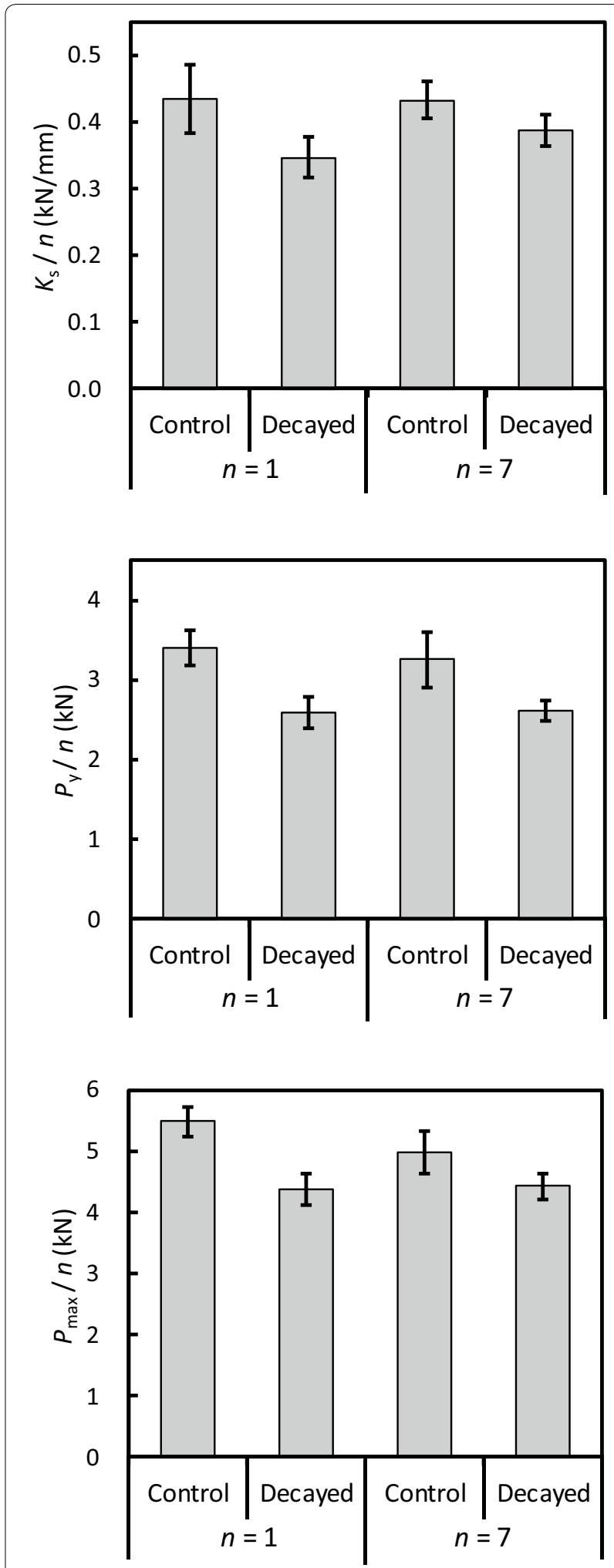

Fig. 13 Comparison of strength properties between screwed joints with 1 screw and those with 7 screws. Note: n: number of screw 
investigated. The extent of the decay was also investigated by means of Pilodyn penetration depth and the decay depth to evaluate shear performance of the screwed joints. The obtained results can be summarized as follows:

1. The differences between decayed and control specimens in $P_{\max }$ and $P_{\mathrm{y}}$ were both significant at the $1 \%$ level. In contrast, the difference in $K_{\mathrm{s}}$ was not significant at the $5 \%$ level, though the mean of $K_{\mathrm{s}}$ of control specimens was higher than that of decayed specimens.

2. Pilodyn penetration depth did not have significant relationships with $K_{\mathrm{s}}, P_{\mathrm{y}}$, or $P_{\max }$ of the screwed joints, because the range of Pilodyn penetration depth was not narrow.

3. The decay depth had a significant inverse correlation with the $K_{\mathrm{s}}$ at the $1 \%$ level. The multiple regression of $K_{\mathrm{s}}$ on the decay depth and $\mathrm{WD}_{\mathrm{h}}$ was significant at the $1 \%$ level. $K_{\mathrm{s}}$ is inferred to be determined by both the decay depth and $\mathrm{WD}_{\mathrm{h}}$. The multiple regressions of $P_{\mathrm{y}}$ and $P_{\max }$ on the decay depth and $\mathrm{WD}_{\mathrm{h}}$ were significant at the $5 \%$ and $1 \%$ level, respectively. Therefore, $P_{\mathrm{y}}$ and $P_{\max }$ are also inferred to be determined by both the decay depth and $-\mathrm{WD}_{\mathrm{h}}$.

4. The shear performance of screwed joints with a screw obtained in this study was compared with those with seven screws obtained in the previous study. The difference between $K_{s}$ of the screwed joints with a screw and those per screw with seven screws was not significant at the $5 \%$ level, regardless of the decay. The differences in $P_{\mathrm{y}}$ and $P_{\max }$ per screw were not significant at the $5 \%$ level as well. Therefore, it is inferred that shear performance of the multiscrew joints could be sufficiently estimated from the results of the loading tests of screw joints with one screw, even if the main members were decayed so long as the extent of decay is the same.

\section{Abbreviations \\ $P_{\text {max }}:$ Maximum load; $P_{\mathrm{y}}$ :Yield load; $D_{\mathrm{y}}$ : Yield slip; $K_{\mathrm{s}}$ : Initial stiffness.}

\section{Acknowledgements}

This work was supported by JSPS KAKENHI Grant Number 17K07870.

\section{Footnote}

Part of this study was presented at the 69th Annual Meeting of the Japan Wood Research Society, Hokkaido, March 2019; and the 18th Symposium on Use of Wood for Civil Engineering, Tokyo, August 2019.

\section{Authors' contributions}

Rintaro Ueda, Kei Sawata, and Ryuya Takanashi performed plan building. Rintaro Ueda and Yoshihisa Sasaki performed specimen preparation and test conduction. Rintaro Ueda, Kei Sawata, and Takanobu Sasaki performed discussion. Rintaro Ueda performed data analysis and manuscript writing. All authors read and approved the final manuscript.

\section{Funding}

This work was supported by JSPS KAKENHI Grant Number 17 K07870.

\section{Availability of data and materials}

The test materials, test method, and the data were recorded as shown in the manuscript. Additional data are available from the corresponding author on reasonable request.

\section{Competing interests}

The authors declare no competing interest associated with this manuscript.

\section{Author details}

${ }^{1}$ Graduate School of Agriculture, Hokkaido University, N9 W9, Sap-

poro 060-8589, Japan. ${ }^{2}$ Research Faculty of Agriculture, Hokkaido University, N9 W9, Sapporo 060-8589, Japan. ${ }^{3}$ Forest Products Research Institute, Hokkaido Research Organization, 1-10 Nishikagura, Asahikawa 071-0198, Japan.

Received: 7 November 2019 Accepted: 21 May 2020

Published online: 29 May 2020

\section{References}

1. Olaf S (2007) Indoor wood-decay basidiomycetes: damage, causal fungi, physiology, identification and characterization, prevention and control. Mycol Progress 6:261-279

2. Frederick GT, Terry LH (1997) Brown-rot wood decay_insights gained from a low-decay isolate of Postia placenta. Plant Pathol 1:1-17

3. Doi S, Nishimoto K (1986) The bending strength and the chemical components of Ezomatsu (Picea jezoensis) wood decayed by the dry rot fungus, Serpula lacrymans. Mokuzai Gakkaishi. 32(9):724-729 (in Japanese)

4. Imamura Y, Fujii Y, Noguchi M, Fujisawa K, Yukimine K (1991) Acoustic emission monitoring during bending test of decayed wood (in Japanese). Mokuzai Gakkaishi 37(11):1086-1090

5. Fujihira M, Nakamura Y, Isoda N, Hikita H (1997) Relationship between decay resistance and changes of bending strength of structural lumber of wood framing construction by fungal attack (in Japanese). Mokuzai Gakkaishi 43(7):589-594

6. Fujita M, Muraguchi Y, lljima Y Y (2002) The remaining strength of decayed Bongossi wood (in Japanese). Mokuzai Gakkaishi 48(1):32-37

7. Abe Y (1949) Decay of coniferous wood caused by Merulius lacrymans and their effect on the compressive strength of the wood (in Japanese). Hokkaido Rinshi Syuho 68:23-28

8. Toda M, Mori M, Ohashi Y, Hirai T (2010) Effects on wood decay on the shear performance of nailed timber joint (in Japanese). Mokuzai Gakkaishi 56(1):41-47

9. Takanashi R, Sawata K, Sasaki Y, Koizumi A (2017) Withdrawal strength of nailed joints with decay degradation of wood and nail corrosion. J. Wood Science 63(2):192-198

10. Scott MK, Robert JL, David VR, Jefferey JM (2005) Effects of decay on the cyclic properties of nailed connections. J Mater Civ Eng 17(5):579-585

11. Mori T, Noda Y, Azuma T, Mori M, Toda M (2014) Evaluation of single shear performance of wood screw joint after compulsive decay (in Japanese). Kouzou Kougaku Ronbunsyu 60:371-375

12. Mori T, Noda Y, Azuma T, Mori M, Toda M, Ishida H (2015) Evaluation of single shear strength performance of wood screw joint driving into compulsive decayed wood. Kouzou Kougaku Ronbunsyu 61:237-241 (in Japanese)

13. Takanashi R, Toda M, Miyauchi T, Mori M, Mori T (2018) Shear strength of multi-screw joints connected to decayed lumber. Mokuzai Gakkaishi 64(3):122-129 (in Japanese)

14. JIS Z (2009) Test methods for timber (in Japanese). Japanese Industrial Standard Association, Tokyo

15. Toda M, Takanashi R, Azuma T, Mori M (2017) Degradation of strength of column-sill joint with decay treatment. J For Prod Res Inst 545:46-50 (in Japanese) 
16. Architectural Institute of Japan (2006) Standard for structural design of timber structures. Architectural Institute of Japan, Tokyo, pp 266-268 (in Japanese)

\section{Publisher's Note}

Springer Nature remains neutral with regard to jurisdictional claims in published maps and institutional affiliations.
Submit your manuscript to a SpringerOpen ${ }^{\odot}$ journal and benefit from:

- Convenient online submission

- Rigorous peer review

- Open access: articles freely available online

- High visibility within the field

- Retaining the copyright to your article

Submit your next manuscript at $\boldsymbol{\nabla}$ springeropen.com 